\title{
A brief note on the history of psychosurgery in Japan
}

\author{
Jiro Nudeshima, PhD, ${ }^{1}$ and Takaomi Taira, MD, $\mathrm{PhD}^{2}$ \\ 'Bioethics Policy Study Group, Minato-ku; and 2Department of Neurosurgery, Tokyo Women's Medical University, Tokyo, Japan
}

In Japan, there has been no neurosurgical treatment for psychiatric disorders since the 1970s. Even deep brain stimulation (DBS) has not been studied or used for psychiatric disorders. Neurosurgery for psychiatric disorders has been thwarted by social taboos for many years, and psychiatrists today seem to simply ignore modern developments and therapies offered by neurosurgery such as DBS. As a result, most patients and their families do not know such "lastresort" options exist.

Historically, as in other countries, frontal lobotomies were widely performed in Japan in the 1940s and 1950s, and some Japanese neurosurgeons used stereotactic methods for the treatment of psychiatric disorders until the 1960s. However, in the 1960 s and 1970 s such surgical treatments began to receive condemnation based on political judgment, rather than on medical and scientific evaluation. Protest campaigns at the time hinged on the prevailing political beliefs, forming a part of the new "left" movement against leading authorities across a wide range of societal institutions including medical schools. Finally, the Japanese Society for Psychiatry and Neurology banned the surgical treatment for psychiatric disorders in 1975. Even today, Japan's dark history continues to exert an enormous negative influence on neurosurgery for psychiatric disorders.

https://thejns.org/doi/abs/10.3171/2017.6.FOCUS17255

KEY WORDS psychosurgery; history; Japan

I $\mathrm{N}$ Japan, there has been no neurosurgical treatment for psychiatric disorders since the 1970s. A discussion about this field of functional neurosurgery can often be regarded as dangerous, even today. This is mainly due to the results of aggressive protest events in the 1960s and 1970s in Japan. However, such historical background is not widely known in abroad. In this brief note, we would like to introduce the history of psychosurgery and its consequences in Japan.

\section{The Beginning of Psychosurgery in Japan}

In November 1938, the first psychosurgical procedure in Japan was performed by Mizuho Nakata (1893-1975), a surgeon and professor at the Niigata Medical College (now the Faculty of Medicine, National University of Niigata).

Nakata graduated from the Medical College of the Tokyo Imperial University and began performing brain surgery after having studied in Europe from 1924 to 1927 . He had further training in neurosurgery under Harvey Cush- ing and Walter Dandy in the United States, from 1935 to 1936.

Nakata's first operations were frontal lobectomies, which he considered a better alternative to lobotomy. From 1938 to 1941 , his team performed 52 procedures (44 for epilepsy including cases with psychiatric symptoms, 5 for schizophrenia, 2 for feeble-mindedness, and 1 for prefrontal tumor). But they could not get good therapeutic outcomes in patients with psychotic disorders, especially in those with chronic schizophrenia. ${ }^{8}$ After these early results, in 1942 Nakata turned to frontal lobotomy. This was also the first trial of lobotomy in Japan.

In 1942 Nakata presented his psychosurgery trials at the national meeting of the Japanese Society of Psychiatry and Neurology (JSPN), but psychiatrists were not interested in psychosurgery at that time. This might have been due to the fact that Nakata was not a psychiatrist but rather a surgeon. In addition, World War II was becoming increasingly complex and was taking an increasing toll on the Japanese population.

ABBREVIATIONS DBS = deep brain stimulation; JSPN = Japanese Society of Psychiatry and Neurology; OCD = obsessive-compulsive disorder. 
It was after the end of World War II that psychosurgery attracted the interest of Japanese psychiatrists. Lobotomy was introduced through oral presentations as well as in medical literature brought by the US occupational officers in 1946 and 1947, and this information was disseminated rapidly. According to a national survey conducted by the JSPN, 2000 patients underwent lobotomy in 28 hospitals through the end of 1949. Results were "good" in 33.9\%, "fair" in $24.3 \%$, "poor" in $28.1 \%$, "worse" in $1.6 \%$, and led to death in $3.1 \% .^{4}$

In Japan, psychiatrists performed lobotomies without surgeon partners in most cases. In those days, many Japanese psychiatrists had gained experience in surgery during their military service in the war. Such experience might have given them the courage to perform the operations by themselves. ${ }^{15}$ In addition, neurosurgery was not yet well established as a discipline in Japan. Without formal training in neurosurgery, psychiatrists learned how to perform a lobotomy from medical literature as well as from surgeons or psychiatrists who had already performed the surgery.

Many psychiatrists had a hand in performing psychosurgery, but Sadao Hirose (1918-2007) performed the greatest number of operations as an individual practitioner. Hirose graduated from the Faculty of Medicine of the Tokyo Imperial University where he joined the neuropsychiatry department. During the war, he served as a naval medical officer in the southern Pacific area, and returned home in 1946. Hirose learned lobotomy from the American medical literature. Then he learned neurosurgery from surgeons of the general hospitals and by studying Nakata's textbook just published at that time..$^{14}$ After a half-year preparation, he began performing frontal lobotomies at the Tokyo Metropolitan Matsuzawa Mental Hospital in 1947 (Fig. 1) (Matsuzawa Hospital was the de facto clinical institution of the neuropsychiatry department of Tokyo University). Until 1957, he performed 400 operations using many variations of lobotomy. Of these procedures, 290 were for schizophrenia (others were for depression, obsessive neurosis, epilepsy, psychopathic behavior, and so on). ${ }^{2}$

In 1957, following the advice of Goesta Rylander, Hirose turned to orbital undercutting. He learned this method from a letter by William Scoville and developed his own modification ("orbito-ventromedial undercutting," Fig. 2). Through 1972, he performed 123 procedures at the Matsuzawa Hospital and the Nippon Medical School (starting in 1960). Of 77 procedures performed until 1963, 34 were for schizophrenia, 11 for explosive epilepsy, 4 for depression, 4 for obsessive-compulsive disorder (OCD), and 8 for aggressive psychopathic behavior. Results were as follows: "symptom free" in 9 cases, "markedly improved" in 22, "moderately improved" in 29 , "slightly improved" in 8 , and "unimproved" in 1, worsening in 0 , and early postoperative death in 0 . Of the 77 patients 38 were able to be discharged to home, 31 remained hospitalized, 6 died long after surgery, and 2 had missing information. ${ }^{3}$

Hirose formed a close friendship with Walter Freeman when they met in 1961 at the Third World Congress of Psychiatry in Montreal. In The Lobotomist, his biography of Freeman, Jack El-Hai noted that Hirose was "a kindred spirit" for Freeman. "Both men's names were synonymous with the practice of psychosurgery in their countries, and

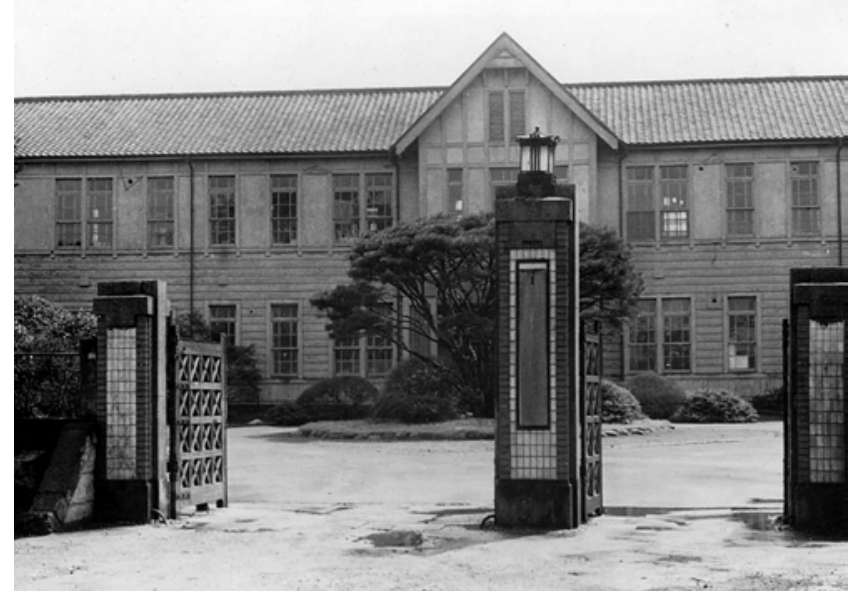

FIG. 1. Photograph of the Tokyo Metropolitan Matsuzawa Hospital. Copyright Yasuhiko Kobayashi Research Album: http://kenkyukaiblog. jugem.jp/?eid=151. Published with permission.

they formed a close bond. They maintained an active correspondence until Freeman's death [in 1972]."' El-Hai refers to Hirose as a "surgeon," but this was not the case. It is true that Hirose was surgically oriented in his practice, but he was a psychiatrist who never trained in neurosurgery.

In addition to lobotomy, other alternative psychosurgical methods were tried by Japanese neurologists and neurosurgeons.

In 1953, Nakata established the Department of Neurosurgery at the Niigata University, the first such department in Japan. Through 1955, his team performed 94 procedures-lobectomy, cingulectomy, amygdalotomy, and lobotomy. ${ }^{11}$

At the same time, stereotactic neurosurgery was being developed in Japan. From 1948 to 1953, Hirotaro Narabayashi (1922-2001), originally trained as a neurologist, developed a stereotactic surgical device and performed 4 operations for psychiatric patients, but he was disappointed with the results and turned his attention to patients with neurological disorders such as Parkinson disease. . $^{12,13}$

Keiji Sano (1920-2011) (Fig. 3), Professor of the Department of Neurosurgery at Tokyo University, also performed stereotactic brain surgery (mainly hypothalamotomy) for aggressive and violent patients with psychosis. ${ }^{16,17}$

\section{Psychosurgery's Condemnation and Disappearance}

In Japan, chlorpromazine was introduced into the psychiatric clinic in 1955-1956. After that, lobotomy and other psychosurgical procedures gradually faded from clinical practice in the 1960 s, mirroring the pattern that occurred worldwide. Hirose summarized this trend concisely as follows: “... psychosurgery became a fashion, but marked decline in its popularity followed as the result of too frequent misuse of standard and transorbital lobotomies, which brought on many unfavorable side effects. Further the appearance of various tranquillizers increased this tendency." 6

There was criticism of psychosurgery among some psychiatrists in the 1940s and $1950 \mathrm{~s},{ }^{10}$ but most admitted 


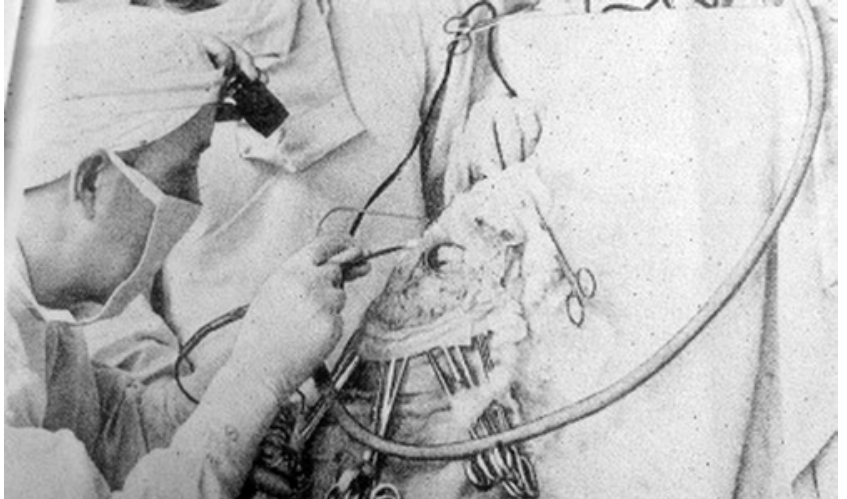

FIG. 2. Hirose performing the undercutting procedure. From Nihon lji Shinpou (Japan Medical Journal), no. 1793, 1958, p 29. Public domain.

lobotomy was an indispensable option because of its usefulness in calming patients in whom other treatments were not successful. However, appropriate quality control of brain surgery was lacking in many psychiatric hospitals in those days, and poor outcomes could not be prevented. Hirose performed surgery in operating rooms, but there were some who operated on patients in simple treatment rooms, especially in local psychiatric hospitals. Neurosurgeons regarded such operations as inappropriate. ${ }^{16}$ Shigeo Watanabe, a neurosurgeon and lecturer at Nagoya University, blamed "those without training in surgery" for performing "blind invasion to the human brain."19

Hirose was also critical of lobotomy for its roughness, and this was the reason why he turned to undercutting. He was confident in his surgical skill. He conceded that antipsychotic drugs were effective, but also regarded them as effecting a "chemical lobotomy." He also thought that there would be patients whose illness would be refractory to these medications. After the era of pharmacotherapy had come, Hirose still believed that psychosurgery would be needed and should come back. ${ }^{5}$

This vision indeed came true in many countries in time, but never in Japan. Fierce opposition to psychosurgery arose in the $1970 \mathrm{~s},{ }^{18}$ when only a few practiced lobotomy or other psychosurgical procedures.

In 1971, Hiroshi Utena, then Chair and Professor of the Department of Neuropsychiatry at Tokyo University, was accused by a dissident department member of malpractice in research involving lobotomy patients that took place in 1951. ${ }^{7}$ After this activist's attack, protest campaigns against psychosurgery occurred in many hospitals and university psychiatry departments across the country by 1974 , which resulted in the 1975 adoption of a resolution condemning psychosurgery by the JSPN. It stated, "Psychosurgery... should not be practiced as medicine." 9

During the same time period, from 1973 to 1980, 5 lawsuits (1 against a university department of neurosurgery and 4 against mental hospitals) were brought by patients and their families with support of advocates, demanding compensation for damage resulting from psychosurgery. ${ }^{14}$ In addition, in 1979, a patient who had undergone cingulectomy killed his doctor's wife and mother-in-law 15 years after surgery. It was inaccurately deemed the "Lobotomy Murder Case" in popular media reports.

As a result of these accusations and scandals, Japanese

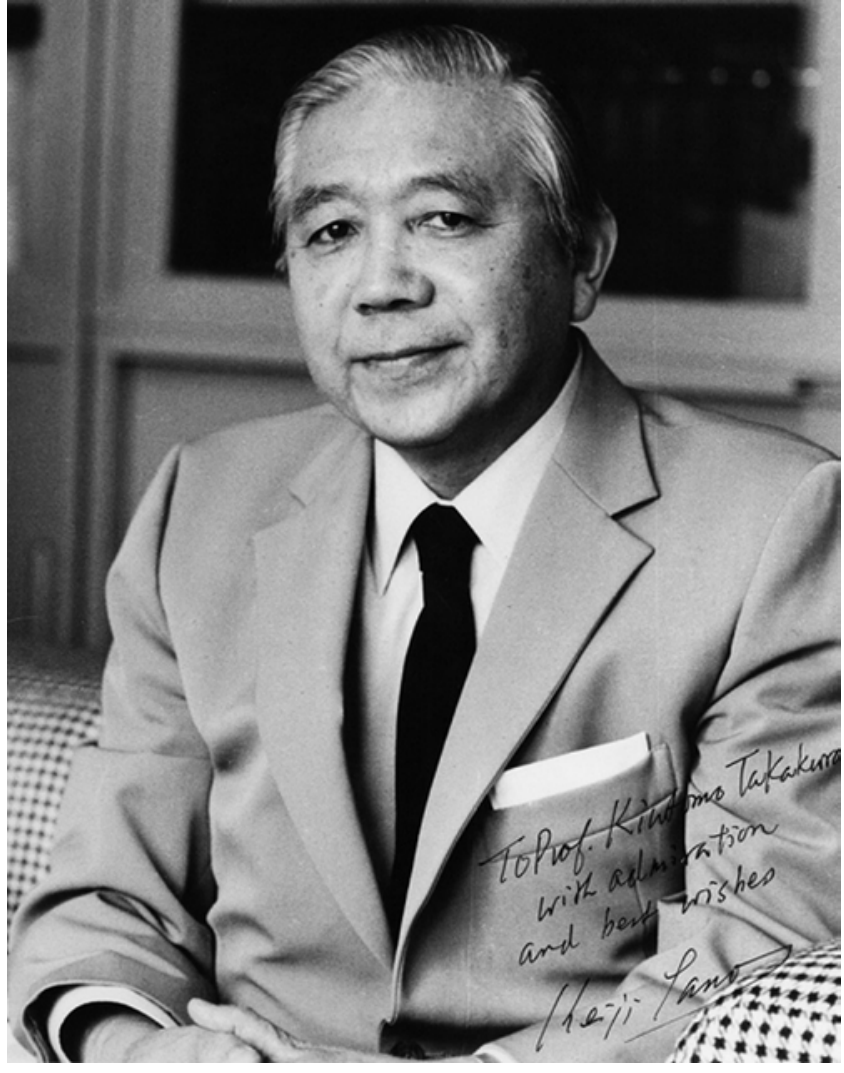

FIG. 3. Photograph of Keiji Sano. From the private collection of Dr. Takaomi Taira.

psychosurgery was stigmatized and its fate sealed under taboo by the end of the 1970s.

Looking back, it seems obvious that political judgment, not medical judgment, was the basis for the condemnation of psychosurgery. Protest campaigns were governed by the prevailing political attitude, and this formed a part of the new "left" movement against leading authorities-across a wide range of society including medical schools (Fig. 4). These protests aimed to deny the power of a chair and professor of a psychiatry department. Psychosurgery was co-opted as a symbol with which to criticize the evils of the "ancient regime."

However, clearly the condemnation of psychosurgery in Japan was not based on sufficient and appropriate clinical data. In its resolution to ban psychosurgery, the JSPN had not conducted even a national survey. As a result, crossinstitutional data on outcome, mortality rate, and adverse effects of psychosurgery are not available. Even the approximate number of procedures in Japan is unknown. Were there thousands? Tens of thousands? More? We will never know.

\section{Psychosurgery's Ongoing Taboo Status}

Sealed under taboo for many years, the facts concerning psychosurgery seem to be lost. This neurosurgical approach has been discredited as a treatment option in psychiatric practice for 30 years or more. Today in Japan, psychiatrists do not inform patients about deep brain stimulation (DBS) 

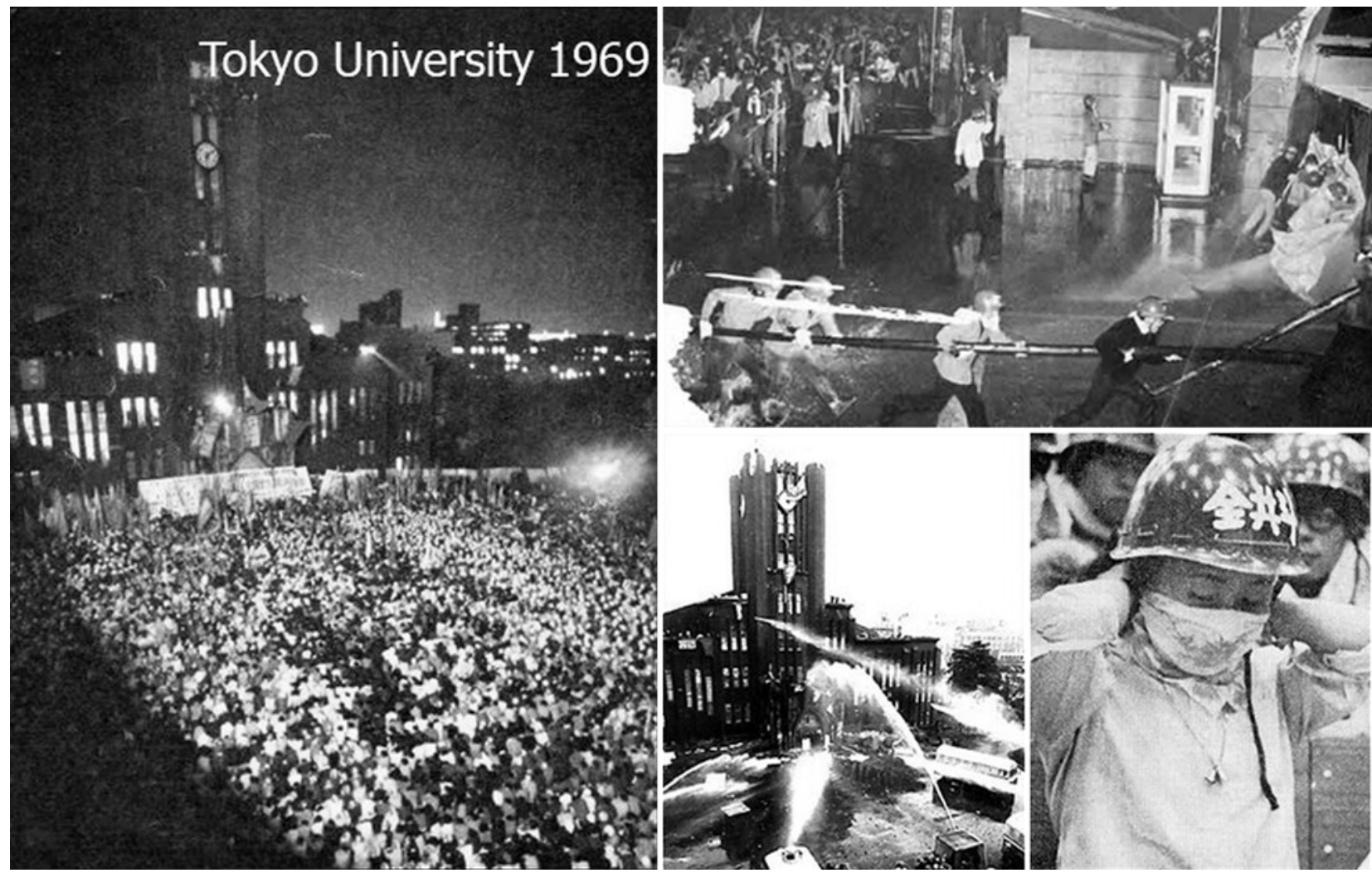

FIG. 4. Photographs showing various protests against authority in the late 1960s and the 1970s. From a private collection of Dr. Takaomi Taira.

or ablative surgery that were developed abroad and have been used more frequently in the recent years. They seem to simply ignore neurosurgical treatments, rather than having judged them inappropriate by medical evaluation. Thus, most patients and their families do not even know that such "last-resort" options exist.

Because of the history of psychosurgery described above, the application of neurosurgical options for mental disorders is a more sensitive problem in Japan than in other countries. For example, a clinical trial of DBS for OCD had been planned at Hamamatsu Medical School since 2006. The trial protocol received IRB approval in 2015, but as of April 2017, the JSPN still held a negative opinion on the matter, and the Hamamatsu DBS-OCD team could not get sufficient support in or out of the school to conduct the study.

\section{Concluding Thoughts}

We suggest that the future advancement of Japanese medicine must be based on a good understanding of the past. Whatever the excesses of psychosurgery were in the past, we should balance this view with a scientifically valid evaluation of the current status of neurosurgery for psychiatric disorders. Japanese psychiatrists must make the effort to fill a more than 30-year gap in knowledge about neurosurgical approaches for psychiatric indications. For their part, Japanese neurosurgeons who want to apply neurosurgical options to cases involving psychological or behavioral disorders must build good communication and mutual understanding with psychiatrists in everyday clinical settings. The goal should be not to promote or persuade but to become acquainted with each other's interests, experience, and concerns first.

\section{References}

1. El-Hai J: The Lobotomist. Hoboken, NJ: Wiley, 2005, p 281

2. Hirose S: [Evaluation of prefrontal lobotomy in schizophrenia.] Seishin Shinkeigaku Zasshi 60:1341-1351, 1958 (Jpn)

3. Hirose S: Orbito-ventromedial undercutting 1957-1963. Follow-up study of 77 cases. Am J Psychiatry 121:1194-1202, 1965

4. Hirose $S$ : Past and present trends of psychiatric surgery in Japan, in Hitchcock ER, Ballantine HT, Myerson BA (eds): Modern Concepts in Psychiatric Surgery. Amsterdam: Elsevier, 1979

5. Hirose S: Present trends in psychosurgery, in López Ibor JJ (ed): Proceedings of the IV World Congress of Psychiatry. New York: Excerpta Medical Foundation, 1968, pp 11561166

6. Hirose S: Psychosurgery 1947-60: evaluation of 450 patients treated by prefrontal lobotomy and a new methof oforbitoventromedial undercutting, in Proceedings of the Third World Congress of Psychiatry. Toronto: University of Toronto Press, 1962, pp 138-141

7. Ishikawa K: [Report of the Ad Hoc Committee on Dr. Ishikawa's accusation of Dr. Utena.] Seishin Shinkeigaku Zasshi 75:848-895, 1973 (Jpn)

8. Itai S: Beobachtung ueber die frontallobektomierten Patienten. Seishin Shinkeigaku Zasshi 46:225, 1942 (Jpn)

9. Japanese Society for Psychiatry and Neurology: [Resolu- 
tion denying psychosurgery.] Seishin Shinkeigaku Zasshi 77:541, 1975 (Jpn)

10. Koshika K: [The results of lobotomy and its critical consideration.] Seishin Shinkeigaku Zasshi 55:91-105, 1953 (Jpn)

11. Matsuo Y: [The study of the neurosurgical procedures to handle the oligophrenic and psychotic patients with restlessness and agitation.] Seishin Shinkeigaku Zasshi 61:12251249,1959 (Jpn)

12. Narabayashi H: Beginning and development of stereotaxic surgery in Tokyo. Confin Neurol 37:364-373, 1975

13. Narabayashi H, Nagao T, Saito Y, Yoshida M, Nagahata M: Stereotaxic amygdalotomy for behavior disorders. Arch Neurol 9:1-16, 1963

14. Nudeshima J: [The sealed past: history of psychosurgery], in Seishin wo Kiru Shujutsu. Tokyo: Iwanami-Shoten, 2012 (Jpn)

15. Okada Y: [History of Psychiatry in Japan.] Tokyo: IgakuShoin, 2002, pp 205-206 (Jpn)

16. Sano K: [The establishment of neurosurgery as a discipline in Japan and its contact with psychosurgery.] Clin Eval 36:147-152, 2008 (Jpn)

17. Sano K, Mayanagi Y, Sekino H, Ogashiwa M, Ishijima B: Results of stimulation and destruction of the posterior hypothalamus in man. J Neurosurg 33:689-707, 1970

18. van Alpen HA: $\mathbf{5 0}$ Years of the World Federation of Neurosurgical Societies (1995-2005). Vaud, Switzerland:
World Federation of Neurosurgical Societies, 2005 (http:// www.wfns.org/WFNSData/Document/Chapter2-4.pdf) [Accessed July 12, 2017]

19. Watanabe S: [Lobotomy and Temporal Lobectomy.] Tokyo: Kanehara Shuppan, 1957 (Jpn)

\section{Disclosures}

The authors report no conflict of interest concerning the materials or methods used in this study or the findings specified in this paper.

\section{Author Contributions}

Acquisition of data: Nudeshima. Analysis and interpretation of data: both authors. Drafting the article: Nudeshima. Reviewed submitted version of manuscript: Taira. Approved the final version of the manuscript on behalf of both authors: Taira. Administrative/technical/material support: Taira. Study supervision: Taira.

\section{Correspondence}

Takaomi Taira, Department of Neurosurgery, Tokyo Women's Medical University, 8-1 Kawada-cho, Shinjuku-ku, Tokyo 1628666, Japan.email: ttaira@twmu.ac.jp. 